\title{
CFD Analysis of Turbocharger Compressor to Study the Effect of Geometry Change on Surge and Performance of Compressor
}

\author{
Shubham Patil, Jagdish, Lokavarapu Bhaskara Rao* \\ School of Mechanical and Building Sciences, VIT University, Chennai Campus, Chennai, 600127, India
}

\begin{abstract}
Turbocharger is used to increase the efficiency of an engine. In the turbocharger, a centrifugal compressor is used. Centrifugal compressor failure has been a main issue in recent years. The failure of the centrifugal compressor is because of surge and stall. Surge occurs because pressure at the receiver is greater than the pressure at the compressor. So, gas flow will reverse and surge occurs. This work-study is based on reducing surge and stall. We can prevent the tendency of surge and stall by changing the factors affecting the change in pressure. We can change the pressure by changing the density of gas, number of impellers, impeller diameter, inlet and volute geometry and flow regulation. Hence, in this paper, we perform the CFD analysis of the centrifugal compressor by changing the geometry.
\end{abstract}

Keywords: centrifugal compressor; CFD analysis; surge and stall

(Submitted on July 19, 2017; First Revised on September 29, 2017; Second Revised on November 9, 2017; Accepted on November 29, 2017)

(C) 2018 Totem Publisher, Inc. All rights reserved.

\section{Introduction}

Turbocharger is used to increase the efficiency of engines. Due to insufficient supply of air, the complete combustion of fuel is not done, leading to increased pollution. Turbocharger is a device that forces air into the engine for complete combustion of fuel, so that the efficiency of the engine will increase. Turbine and centrifugal compressor are the two main parts of the centrifugal compressor. The turbocharger uses the exhaust gas to run the turbine. Turbine will generate the power; this power is used to run the compressor up to 1.5 lack rpm. The compressor speed is nearly 30 times faster than the engine. The compressor will suck the air and force it to the combustion chamber. Fig1 shows how the turbocharger works.

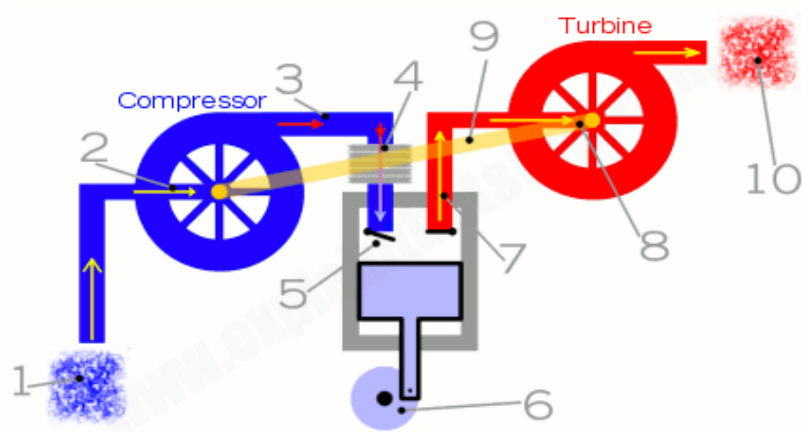

Figure 1. Turbocharger working

In recent years the failure of turbocharger is due to surge that occurs in the compressor. When the compressor impeller blade rotates, it sucks the air from the outside toward the eye of impeller at relatively low velocity. The impeller blade rotates with very high velocity so that it increases the velocity of the air. Then, the high velocity air comes into the diffuser, which converts the high velocity air to high pressure, which increases the pressure outside of turbocharger, leading to reversed flow 
surge in the compressor. The surge will occur because the pressure at the outlet is greeter than the pressure at the inlet. High pressure at the outlet will create high vibrations, leading to failure of the compressor. Surge occurs not only due to the pressure, but also a sudden load change and use of a faulty injector while changing the impeller blade. Chehhat Abdelmadjid, et al [1] has done the CFD Analysis of the Volute Geometry Effect on the Turbulent Air Flow through the Turbocharger Compressor. In this work numerical analysis has been done by changing the volute i.e. circular cross section with tangential inlet location, circular cross section with symmetrical inlet location, and semi-circular cross section with tangential inlet location. By changing volute geometry, they concluded that peak efficiency is maximum at tangential inlet, operating range is maximum at circular cross section inlet and non-uniform pressure is observed in high flow rate condition. J. Galindo, et al [7] studied the effect of the inlet geometry on performance, surge margin and noise emission of an automotive turbocharger compressor. At the inlet of compressor, various types of geometry are assembled. In this work, they studied the straight duct, a tapered duct, and a convergent nozzle. They conducted the experimental tests i.e. steady and transient on an engine, and observed that the straight duct is most likely to enter into the surge line and isotropic efficiency is less. The tapered duct improves the surge margin and improves the isotropic efficiency, and convergent gives the greatest improvement in isotropic efficiency as compare to other geometries. H. Mohtar et al [10] studied the Effect of Diffuser and Volute on Turbocharger Centrifugal Compressor Stability and Performance. To delay the diffuser stability, two different techniques are used i.e. grooved and pinched diffuser. The effect of pinched diffuser is to shift the surge line to low flow rate during pressure drop through the compressor, and the effect of the grooved diffuser is to increase the pressure while flow rate is increasing. Retracting volute tongue on compressor performance is also studied which improves the compressor efficiency and pressure line at high flow rate. Xinqian ZHENG et al [12] studied the investigation of surge and stall in a turbocharger centrifugal compressor with a vanned diffuser. From the experiment, they saw that when centrifugal compressor works at a low speed it experienced stable condition, stall and deep surge with decreasing mass flow rate. When the compressor is at high speed, it experienced stable condition to mild surge, and deep surge at decreasing mass flow rate. Glovannl Ferrara, et al [3] studied the rotating stall of centrifugal compressor with a vanless diffuser. They did the experimental analysis on different parameters that influence the phenomenon of stall evolution. From the experiment they observed that pinch geometry does not affect stall evolution, and that different diffuser width also does not affect stall. Mach number is scales the stall frequency which influence on stall pattern with short diffuser and changing the diffusion ratio will more affecting on stall pattern and stall inception point. Reza S. Abhar [2] studied the Flow Structure and Stability of a Turbocharger Centrifugal Compressor. In this study, they concluded that tip clearance width of diffuser has a dominating effect on the formation of secondary flow in the diffuser, and that flow pattern is influenced by mass flow rate and tip gap. By using this experimental study, they studied the aerodynamic behaviour and stability of small scale highly loaded centrifugal compressor. Ahti Jaatinen-Varri, et al [8] studied centrifugal compressor vanless diffuser width. Seven different diffusers, where one is un-pinched and all other six are pinched diffusers, are used in this study. By changing diffuser length and redesigning the volute, the performance achieved is greater than that of the pinched diffuser study. Manthan Kumar et al [9] studied the Effect of Creating Turbulence on the Performance of Catalytic Converter. In this paper, they studied the effect of turbulence devices on catalytic converter and noted that pollution rate is decreased. D. R. Prajapati and Gurpreet Singh [11] studied the Effect of Blend Fuels on the Mechanical and Volumetric Efficiencies in CVCRM Engine Test Rig. In this paper, they studied the volumetric efficiency by using bio fuel and petrol.

\section{Objectives}

- Study the surge by using vaned diffuser and study the performance of the centrifugal compressor at different rotating speeds.

- Study the surge by changing volute and inlet geometry.

\section{Methodology}

Figure 2 shows the methodology. The first phase of the study is problem definition and a literature survey of turbocharger. The next phase is study surge phenomenon. "Experimental investigation of surge and stall in a turbocharger centrifugal compressor with a vaned diffuser" in this paper they done experiment study, on same model we did analysis for validation. After validation, we change the geometry of volute with the same constraints and study the surge phenomenon. The need for studying turbocharger is to increase performance of centrifugal compressor by reducing the surge in the compressor. To reduce surge, we used rectangular volute instead of circular volute.

\section{Problem Definition}

The failure of the centrifugal compressor is due to the surge, i.e. the reverse flow of gas from the receiver to the centrifugal compressor. Therefore, to avoid the failure of the compressor, we should know what the mass flow rate and rotating speed is when surge occurs. 


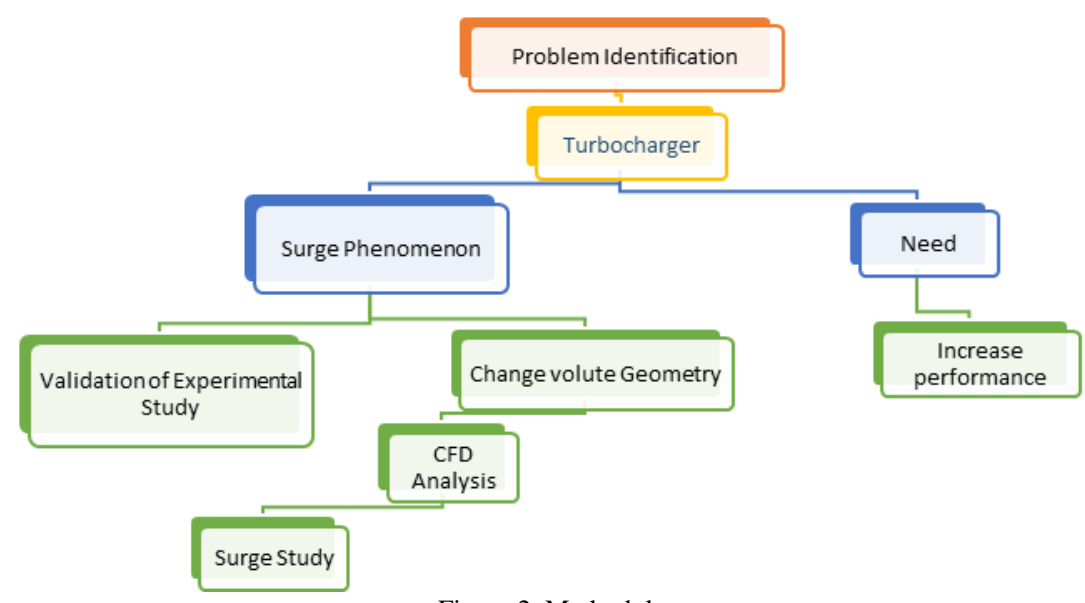

Figure 2. Methodology

\section{Engine specification and compressor dimension}

In this work, first we validate the experimental result of the paper: "Experimental investigation of surge and stall in a turbocharger centrifugal compressor with a vaned diffuser". In this paper, they used one centrifugal compressor, which used a I.C. engine with the following specifications:

Engine type: diesel

Maximum power: $120 \mathrm{~kW}$ (163 hp) @ $3600 \mathrm{rpm}$.

Maximum torque: $340 \mathrm{Nm} @ 2000 \mathrm{rpm}$.

Compressor used in this paper has a circular volute and vaned diffuser with the following dimensions shown in Table1.

Table 1. Dimension of compressor

\begin{tabular}{|c|c|}
\hline PART NAME & DIMENSION \\
\hline Impeller exit diameter & $100 \mathrm{~mm}$ \\
\hline Impeller tip width & $2.55 \mathrm{~mm}$ \\
\hline Inlet shroud diameter & 62.70 \\
\hline Number of blades & 16 \\
\hline Diffuser vane & 16 \\
\hline Diffuser width & 3.98 \\
\hline Volute exit diameter & $65 \mathrm{~mm}$ \\
\hline
\end{tabular}

After matching the results of the above centrifugal compressor, we changed the geometry of the compressor, i.e. we used the rectangular volute instead of the circular volute.

\section{Surge phenomenon in centrifugal compressor}

Turbocharger is used to increase the efficiency of engines, leading to $50 \%$ engine power increase. Surge occurs in the compressor because of sudden loading and unloading of the engine and the reverse flow of gas in the compressor. In automotive application, load variation on turbocharger is continuously changing because of changing flow rate. Surge occurs due to the reverse flow of gas in the compressor, i.e. pressure at the outlet is greater than pressure at the inlet. By using the characteristics curve, we know if surge occurred in compressor. The curve is plotted as pressure ratio vs. flow rate. Figure 3 shows the characteristic curve of compressor. Figure 3 shows the surge line, surge marine, surge control line, constant efficiency line and chocking line.

- Surge point: The peak point on the characteristic curve is called the surge point.

- Surge line: Surge line is the line that connects the surge points $(\mathrm{S})$ on each characteristic curve corresponding to different constant speeds.

- Surge control line: Surge control line is the line that works as the indicating line for the surge control mechanism so that surge can be prevented in the system and proper steps can be taken.

- Surge margin: Surge margin is the indicator to show how close the system is to the surge. 
- Chock point: Choking is the condition that occurs in the compressor in which it operates at very high mass flow rate and flow through the compressor can't be further increased as Mach number at some part of the compressor reach to unity i.e. to sonic velocity and the flow is said to be choked.

- Chock line: Choke line is the line joining the choke points on different constant speed lines

- Constant efficiency lines: Constant efficiency lines are the elliptical shaped curves in the compressor characteristic curve along which the efficiency of the compressor remains constant.

- Maximum allowable speed: Is the maximum speed at which the compressor can work properly, and beyond this speed limit stress and vibrations in the compressor cross the prescribed limit. This can damage the compressor and to control this, the compressor's speed is lowered.

Minimum required speed: Is the minimum speed at which the compressor should operate, and below this limit the compressor cannot increase the pressure of inlet fluid and goes into idle condition.

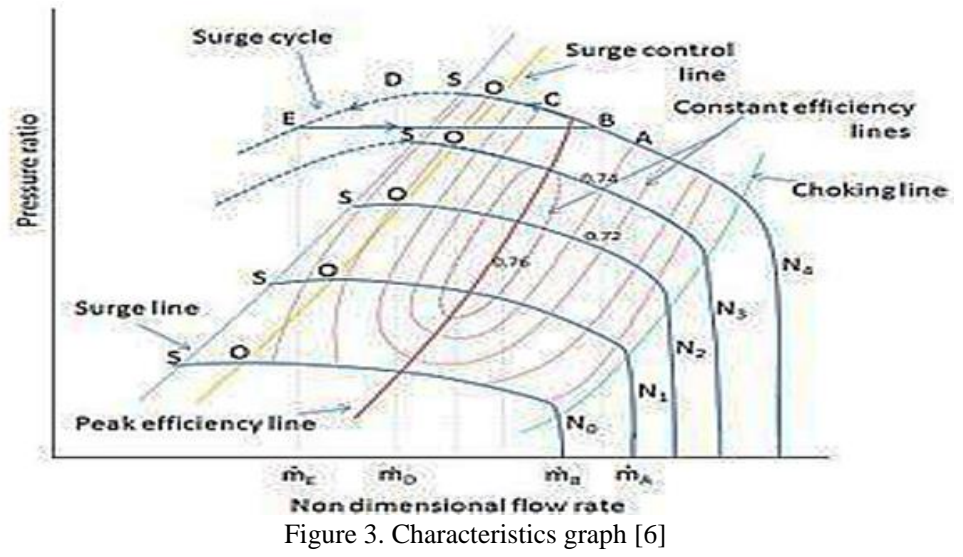

By running the CFD analysis, we can find out the pressure at inlet and pressure at outlet at different rotating speeds. Next, we can plot the point on characteristics curve at what rotating. Speed what is the pressure ratio at what flow rate, we observed point location. If the point occurs on the surge line, then surge will occur. In I.C., engine turbocharger mass flow rate is below $0.1 \mathrm{Kg} / \mathrm{s}$ and the pressure is up to 3 for diesel engine. If the mass flow rate goes on decreasing means, the surge will occur.

\section{Modeling of centrifugal compressor}

For modelling of centrifugal compressor, we used SOLIDWORKS software. From Table1 we know the dimensions. Fig.4 shows modelling of the centrifugal compressor with square and rectangular volute.

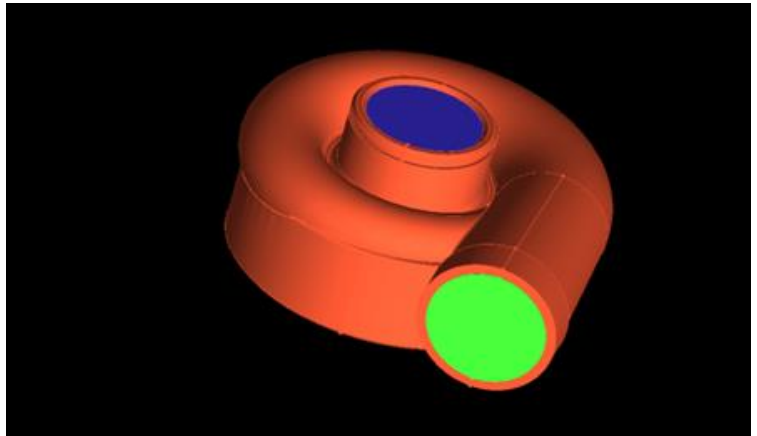

(a) Circular volute compressor

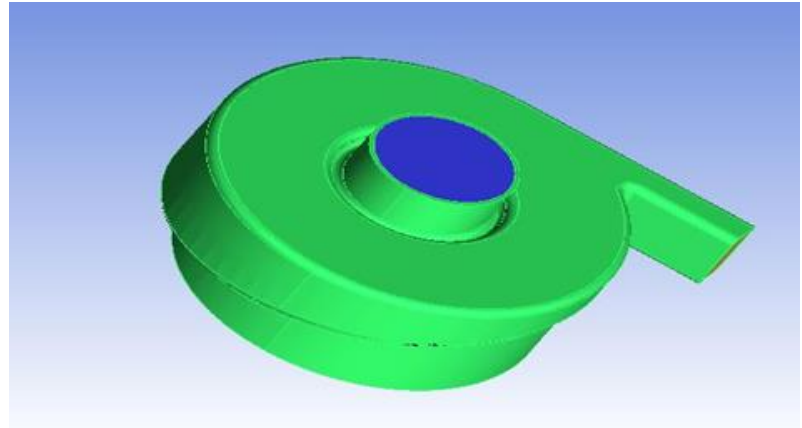

(b) Rectangular volute compressor

Figure 4. Modeling compressor

\section{Meshing of centrifugal compressor}

For the meshing, we use the tetrahedral mesh element because the geometry is complex and we cannot use a lower order of mesh element. If we use the hex mesh, the mesh connectivity will not be good, so we use the tetrahedral mesh element to get good mesh connectivity and fine mesh. The number mesh element used in compressor assembly meshing is 467321 and the 
total number of node is 96639. The following Figure 5(a) shows the meshing of a circular cross-section compressor. The meshing is done in ICEM. We created the solid body point for each solid part such as impeller, volute, diffuser and fluid body point for air that is flowing through the volute. The Figure 5(b) shows the meshing of a rectangular cross-section of the compressor having 738785 mesh elements and 117803 nodes.

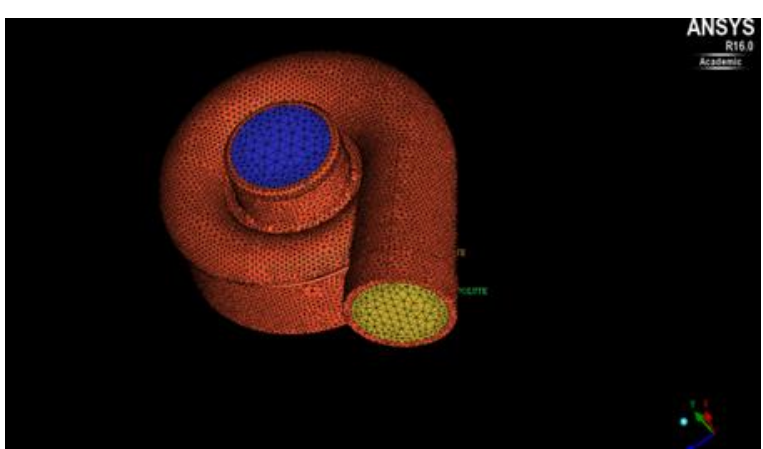

(a) Circular volute compressor

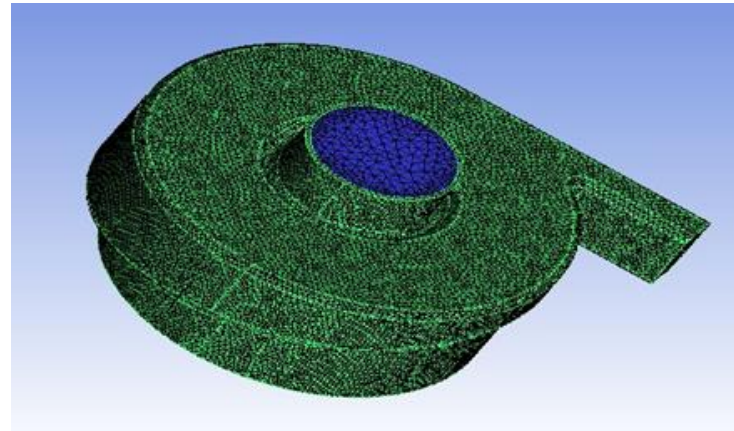

(b) Rectangular volute compressor

Figure 5. Modeling compressor

\section{Results}

\subsection{CFD analysis of compressor}

For analysis of the compressor we used FLUENT as a simulation tool. The first step in fluent is to check the mesh. Figure 6 shows the checking of mesh quality, if the minimum and maximum volume are negative, then mesh quality is not good. The second step is to select the solver and model. Pressure-based solver traditionally has been used for incompressible and mildly compressible flows. Based on Reynolds number we can choose the model. The $\operatorname{Re}>2000$, so we chose the turbulent model. There are many turbulent models available. We choose the K- $\varepsilon$ [4] realizable model. Then next step is to give the material. The material for the fluid is used. The compressor body is AISI4330. Then, we gave cell-zone condition for body point, which was created during meshing. For fluid body point we gave fluid material. For the solid impeller body point we specified the material and enabled the frame motion, and gave rotational velocity in rpm. We have to check the origin of the impeller and give the coordinate, and then rotate in the X-axis so we give rotation axis one and others zero. The other parts of compressor are stationary so need to give any cell-zone condition only we have to select the material. After cell-zone condition we have to give the boundary condition. The inlet and outlet boundary condition is very important. The inlet of compressor is open into the atmosphere, so we have to give atmospheric boundary condition; the inlet of compressor is pressure inlet. The pressure at inlet is 1 bar. Then, we have to find out the pressure at outlet so our outlet is pressure outlet. For impeller we have to enable the rotational wall motion. The next step is obtaining the solution. For this we choose the simple algorithm method and momentum and the other equation is solved by second order. We monitor the volume flow rate at the outlet. The solution is initialized by hybrid initialization. After running the problem up-to converges to the 10-5 residue, we check the different counter plot. This post processing is done by TECHPOLT software.

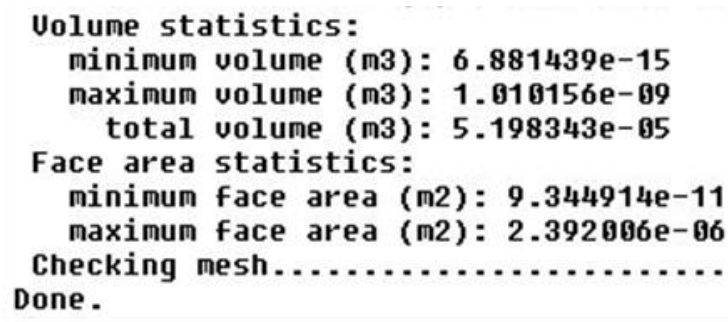

Figure 6. Mesh check

\subsection{For circular volute cross-section}

Figure7 (a) and (b) show the pressure counters at 90000 and 67000 rpm and Figure8 (a) and (b) show stream line respectively, i.e. velocity flow of compressor. From this counter plot, we get the value of pressure at the outlet shown in Table2. From Table 2 we get the pressure ratio if we plot the point on the characteristic graph. Figure 3 shows the location of points and tells us when surge will occur in compressor. 


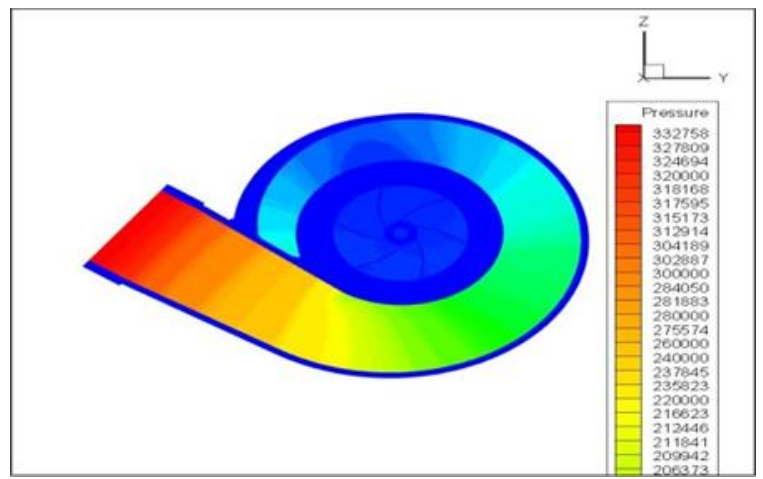

(a) Pressure at 90,000 rpm

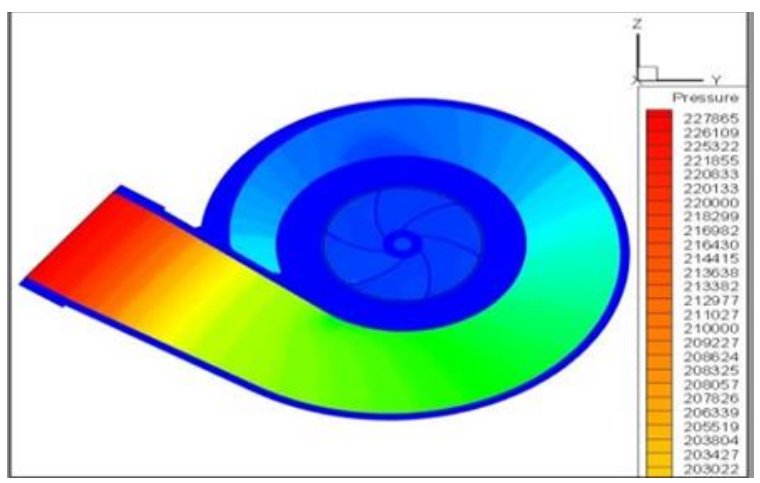

(b) Pressure at $67,000 \mathrm{rpm}$

Figure 7. Pressure
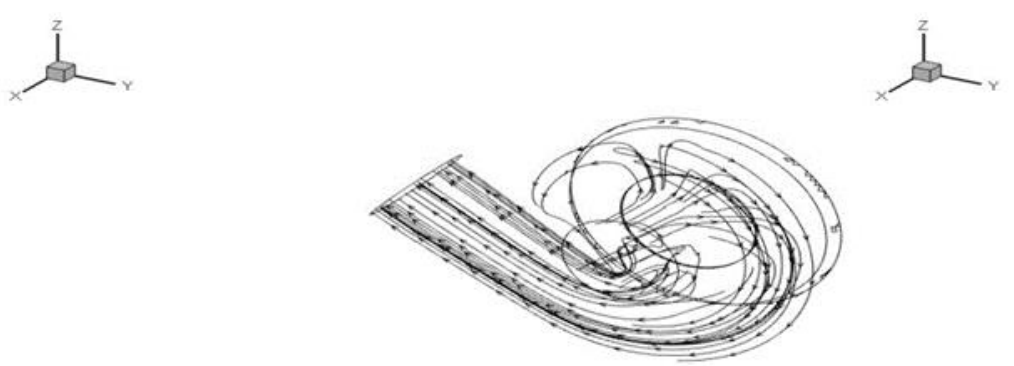

(a) Stream line at 90,000 rpm

Figure 8. Stream lines

(b) Stream lineat 67,000 rpm

\subsection{For rectangular cross-section}

Figure 9 (a) and (b) show the pressure counters at 67000 and 90000 rpm and Figure 10 (a) and (b) show stream line respectively.

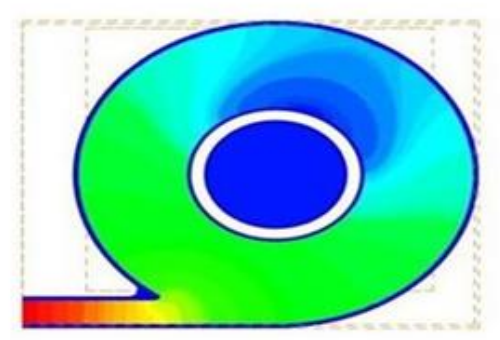

(a) Pressure counter at $67,000 \mathrm{rpm}$

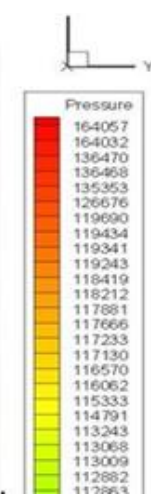

Figure 9. Pressure

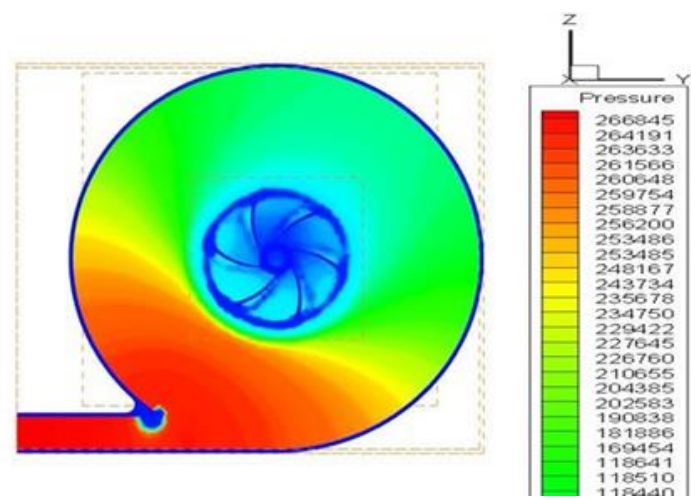

(b) Pressure counter at 90,000 rpm 


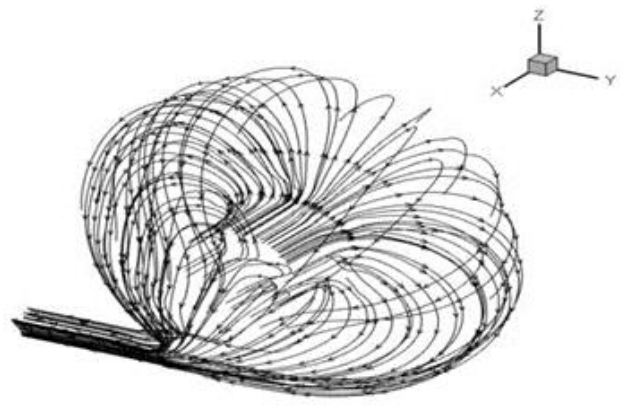

(a) Stream line at $67,000 \mathrm{rpm}$

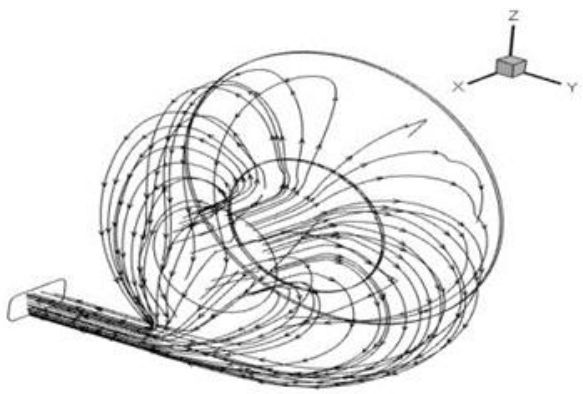

(b) Stream lineat $90,000 \mathrm{rpm}$

Figure 10. Stream lines

Figure 11 (a) shows the performance graph of centrifugal compressor with circular volute. In this graph 67000 and 90000 rpm speed line is plotted by mass flow rate vs. pressure ratio. At $90000 \mathrm{rpm}$, the pressure ratio is very high when compared to $67000 \mathrm{rpm}$. The graph shows two $90000 \mathrm{rpm}$ : one is the experimental result line and the other is the analysis line. These two lines have a closer result, so we can say that at $90000 \mathrm{rpm}$, the result is valid. Similarly, for $67000 \mathrm{rpm}$, both experimental and analysis results are in case of circular volute.

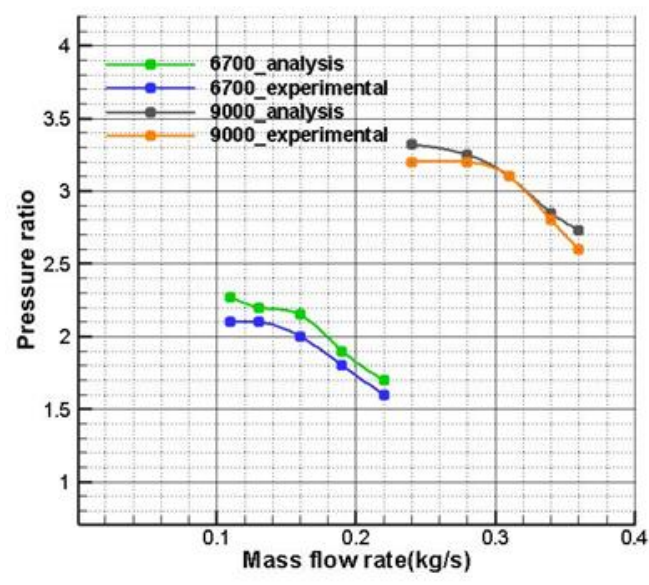

(a) Circular volute

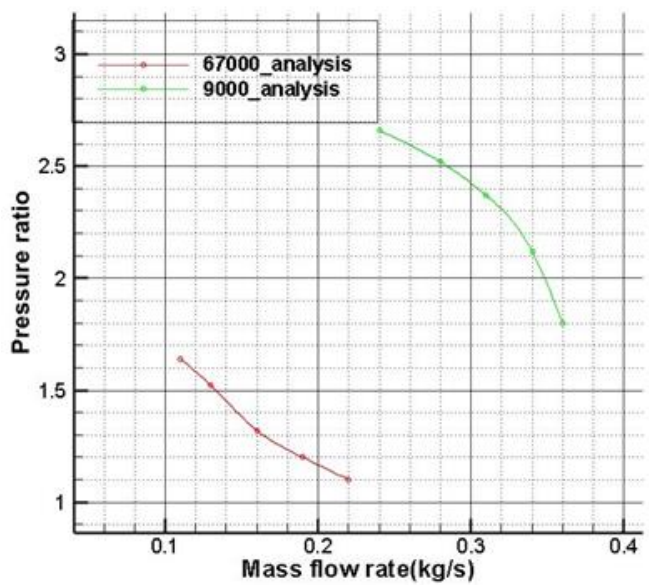

(b) Rectangular volute

Figure 11. Performance

These two graphs show the performance of centrifugal compressor with circular and rectangular volute. From these two graphs, we know the surge will occur in circular volute at $90000 \mathrm{rpm}$ with pressure ratio 3.20 shown in Table 2 and at 67000 rpm with pressure ratio 2.10. However, in the case of the rectangular compressor, surge will not occur at both 90000 and $67000 \mathrm{rpm}$.

Table 2. Pressure ratio at different speed

\begin{tabular}{|c|c|c|c|}
\hline \multirow{2}{*}{ Cross-section } & Speed & Experimental Pressure ratio [12] & Analysis pressure ratio \\
\hline \multirow{2}{*}{ Circular } & 67000 & 2.10 & 2.27 \\
\cline { 2 - 4 } & 90000 & 3.20 & 3.32 \\
\hline \multirow{2}{*}{ Rectangular } & 67000 & - & 1.64 \\
\cline { 2 - 4 } & 90000 & - & 2.66 \\
\hline
\end{tabular}

\section{Conclusions}

We simulated the Experimental investigation of surge and stall in a turbocharger centrifugal compressor with a vaned diffuser [12] and saw results near the experimental result shown in Table2 and Figure 11. After simulating the same case for the rectangular volute compressor and same cross-sectional outlet and similar condition, it is seen that the pressure generated at the outlet of compressor is comparatively lower than the pressure outlet at the compressor having a circular cross-section. Therefore, we can say that surge occurs at 3.2 bar and 2.1 bar for $90000 \mathrm{rpm}$ and $67000 \mathrm{rpm}$ respectively and that performance 
also decreases as shown in Figure 11 (a). But in case of the square volute compressor, surge will not occur so the performance of compressor is increased as shown in Figure 11 (b).

\section{References}

1. C. Abdelmadjida, S. A. Mohamedb, B. Boussad, "CFD Analysis of the Volute Geometry Effect on the Turbulent Air Flow through the Turbocharger Compressor,” Energy procedia, vol. 36, pp.746-755, 2013.

2. R. S. Abhari, "Flow Structure and Stability of a Turbocharger Centrifugal Compressor," Diss. ETH Nr. 16605, 2006.

3. L. Baldassarre, G. Ferrara and L. Ferrari, "Rotating Stall in Centrifugal Compressor Vaneless Diffuser: Experimental Analysis of Geometrical Parameters Influence on Phenomenon Evolution" International Journal of Rotating Machinery, vol. 10, No. 6, pp. 433-442, 2004

4. A. Chehhat, M. Si-Ameur, B. Boumeddane, E. Abo-Serie, S. Boulahrouz, "Numerical investigation of diffuser solidity effect on turbulent airflow and performance of the turbocharger compressor," Applied and computational Mechanics, Vol. 10, No. 2, pp.7996, 2016.

5. S. Bhardwaj and K. K.Gupta, "Centrifugal Compressor Analysis by CFD," International Journal of Science and Research (IJSR), Vol. 3, No. 11, November 2014.

6. X. Fang, "Empirical models for efficiency and mass flow rate of centrifugal compressors," International journal of refrigeration, vol. 41, pp. 190-199, May 2014.

7. J. Galindoa, A. Tiseiraa, R. Navarroa, D. Taria, C.M. Meanob, "Effect of the inlet geometry on performance, surge margin and noise emission of an automotive turbocharger compressor," Applied Thermal Engineering, Vol. 110, pp. 875-882, January 2017.

8. A. Jaatinen-Varri, P. Roytta, T. Turunen-Saaresti and A. Gronman, "Experimental study of centrifugal compressor vaneless diffuser width," Journal of Mechanical Science and Technology, vol.27, no.4, pp. 1011-1020, September 2012.

9. M. Kumar, M. Bhandwal, M. Sharma, A. Verma, U. Srivastava and R. K. Tyagi, "Effect of Creating Turbulence on the Performance of Catalytic Converter," International Journal of Performability Engineering, Vol. 12, No. 2, pp. 115-120, March 2016.

10. H. Mohtar, P. Chesse, D. Chalet, J.-F. Hetet and A.Yammine, "Effect of Diffuser and Volute on Turbocharger Centrifugal Compressor Stability and Performance: Experimental Study," Oil \& Gas Science and Technology - Rev. IFP Energies nouvelles, Vol. 66, pp. 779-790. 2011.

11. D. R. Prajapati and G. Singh, "Effect of Blend Fuels on the Mechanical and Volumetric Efficiencies in CVCRM Engine Test Rig," International Journal of Performability Engineering, Vol. 10, No. 5, pp. 511-520, July 2014.

12. X. Zheng, Z. Sun, T. Kawakubo, H. Tamaki, "Experimental investigation of surge and stall in a turbocharger centrifugal compressor with a vaned diffuser" Experimental Thermal and Fluid Science, Vol. 82, pp. 493-506, April 2017. 